\title{
A taxa de câmbio real e a restrição externa: uma proposta de releitura com elasticidades endógenas
}

\author{
MARCOS ADOLFO RIBEIRO FERRARI \\ FÁBIO NEVES P. FREITAS \\ NELSON BARBOSA FILHO*
}

\begin{abstract}
Real exchange rate and external constraint.
This paper investigates a topic of the agenda about growth models, emphasizing the elaboration of an external constrained model with endogenous elasticity, with an emphasis on real exchange rate level as main tool for the economic development. The model is anchored in Kaldor, Thirlwall and Barbosa Filho's models and it will demonstrate that external constraint changes in the course of time.

Keywords: balance of payments constraint; elasticities and real exchange rate.

JEL Classification: F41; F43.
\end{abstract}

\section{INTRODUÇÃO}

Este artigo visa envidar esforços para produzir algo que permita avançar na formulação de um modelo teórico com elasticidades endógenas, no qual a taxa de câmbio real passa a ser uma variável relevante na determinação da taxa de crescimento de longo prazo, dando ênfase ao seu nível e não à sua variação. A hipótese básica é que o manejo da taxa de câmbio real pode gerar efeitos que transcendem o ajuste da demanda agregada no curto prazo, alterando as elasticidades de forma a modificar a relação de longo prazo entre a taxa de crescimento do produto doméstico e a taxa de crescimento da economia mundial. Tendo em vista ser um tema vagamente explorado na literatura sobre crescimento econômico com restrição

\footnotetext{
* Professor do Instituto Federal do Espírito Santo IFES. E-mail: marcosferrari74@gmail.com; Professor do Instituto de Economia da Universidade Federal do Rio de Janeiro IE/UFRJ. E-mail: fabio@ie.ufrj.br; Professor do Instituto de Economia da Universidade Federal do Rio de Janeiro IE/UFRJ. E-mail: nhbarbosa@gmail.com. Submetido: 10/janeiro/2012; Aprovado: 1/março/2012.
} 
externa, procurar-se-á formalizar a ideia de forma simplificadora, formando a base para futuros avanços nessa linha de pesquisa. A base do modelo será Kaldor (1970 [1978]), Thirlwall (1979) e Barbosa-Filho (2001. a, 2006), na qual serão introduzidas mudanças em suas hipóteses e incorporadas algumas das ideias subjacentes a outros modelos.

Williamson (2003) e Balassa (1993) representam uma corrente teórica que argumenta a favor da utilização da taxa de câmbio real como ferramenta para o desenvolvimento econômico (Development Strategy Approach). Um argumento semelhante aparece em Woo (2004), segundo o qual a estratégia de desenvolvimento dos países asiáticos esteve relacionada à manutenção de tarifas sobre importações e subsídios para exportações no mesmo nível, favorecendo a produção de tradables e o desenvolvimento de uma indústria local tecnologicamente sofisticada e competitiva no mercado mundial (outward-oriented trade regime).

Gala (2006) associa o sucesso da política externa dos países asiáticos à adoção de ciclos de depreciação do câmbio real (current account regions), enquanto o fracasso dos países latino-americanos deve-se à adoção de ciclos de apreciação do câmbio real (capital account regions) ${ }^{1}$. Nesse último caso, Bresser e Nakano (2003) argumentam que a estratégia de crescimento com poupança externa veio acompanhada de apreciações cambiais, aumentando temporariamente os salários reais e o consumo (estratégia conhecida na literatura como "populismo cambial" ou "distributivismo ingênuo"), tendo como resultado a redução da poupança doméstica e aumento do débito externo ${ }^{2}$. Frenkel (2004) argumenta que a adoção da política cambial nos países da América Latina (Argentina, Brasil, Chile e México) para controlar a inflação, num período de liberalização financeira ${ }^{3}$, provocou uma instabilidade da taxa de câmbio real, associando-a a efeitos negativos sobre o nível de emprego e outros aspectos da performance econômica. Frenkel e Taylor (2006) mantêm a mesma linha de raciocínio, enfocando o papel que a estabilidade da taxa de câmbio real num nível competitivo (subvalorizado) pode exercer sobre a alocação de recursos.

Barbosa-Filho (2006), num modelo à la Thirlwall, aponta para os riscos relacionados à adoção do regime de metas de inflação num contexto de taxa de câmbio real apreciada. A ideia básica é que normalmente os ciclos de câmbio real aprecia-

\footnotetext{
${ }^{1}$ Tais denominações foram empregadas por Dooley et al. (2003).

${ }^{2}$ Sobre o assunto, ver também Bresser-Pereira e Varela (2004). Para uma análise a partir do novo desenvolvimentismo, ver Bresser-Pereira (2011).

${ }^{3}$ A adoção da política cambial para a estabilização da economia nos países latino-americanos geralmente vem acompanhada de uma política de juros elevados para garantir o influxo de capitais necessário à manutenção da apreciação cambial e ao fechamento do balanço de pagamentos. Tal influxo reforça os ciclos de apreciação cambial e os efeitos negativos sobre o desenvolvimento econômico. Isso leva Williamson (2005) a colocar em discussão a possibilidade de paralisação desse influxo. Da mesma forma, tal fato faz com que Taylor e Frenkel (2006) recomendem medidas de controle de capitais para assegurar à política cambial um papel importante no processo de desenvolvimento econômico.
} 
do são acompanhados de crises financeiras e fortes desvalorizações cambiais, o que romperia o regime de metas de inflação e desestabilizaria a economia. No mesmo trabalho, inspirado por Woo (2004) e Frenkel e Taylor (2006), o autor chama a atenção para o fato de que a taxa de câmbio real pode ser um importante instrumento para promover o crescimento e o desenvolvimento econômico.

Para avançar nesses modelos, um caminho seria analisar o papel do nível da taxa de câmbio real sobre as elasticidades preço e renda das exportações e importações, e daí seus impactos sobre a relação entre a taxa de crescimento do produto doméstico e a taxa de crescimento da economia mundial. Tal proposição advém do fato de que, mesmo considerando a taxa de crescimento da taxa de câmbio real igual a zero no longo prazo, seu nível seria importante por causa de seus efeitos sobre os preços relativos tradables/non-tradables. Dessa forma, duas hipóteses serão feitas aqui: 1) trata-se de uma pequena economia semi-industrializada e aberta, sendo que o conhecimento tecnológico concentra-se nas exportações, que se dividem em tradables low tech e tradables high tech, cabendo à segunda categoria a responsabilidade pela geração de desenvolvimento econômico ${ }^{4,5} ; 2$ ) as elasticidades são endógenas e se modificam no decorrer do tempo devido ao efeito composição, que depende do nível da taxa de câmbio real. A ideia é que a manutenção da taxa de câmbio real num nível estável e competitivo altera as elasticidades no longo prazo num sentido que melhore a posição de comércio de um país em relação ao resto do mundo.

O artigo será dividido da seguinte forma. Na próxima seção, serão apresentadas as definições e as hipóteses fundamentais do modelo. A terceira seção será destinada à releitura do modelo de Thirlwall (1979) a partir da incorporação de uma regra para as variações na taxa de câmbio real e da endogeneização das elasticidades renda das exportações e importações. Na quarta seção, serão verificadas as mudanças ocasionadas na releitura do modelo de Thirlwall (1979) com a incorporação dos efeitos Kaldor-Verdoorn e Harrod-Balassa-Samuelson. Na última seção, seguem algumas notas a título de conclusão.

\footnotetext{
${ }^{4}$ Formalmente, a decomposição será feita apenas nas exportações, considerando implícito o fato de que uma mudança na pauta de exportações gera uma mudança na estrutura produtiva doméstica.

${ }^{5}$ Essa hipótese opõe-se frontalmente à hipótese adotada por Rodrik (1986) de que o conhecimento tecnológico concentra-se nas importações, justificando a adoção de uma política de abertura da economia e de apreciação da taxa de câmbio real, o que possibilitaria gerar crescimento econômico via externalidades existentes nas importações. Todavia, algumas experiências, a brasileira nos anos 1990, por exemplo, mostram que os resultados não condizem com o modelo, pois a adoção dessas medidas não mudou o perfil da produção doméstica: o Brasil continua a ser um exportador de commodities! Países que adotaram um câmbio subvalorizado (Coreia, Cingapura, China), passaram por transformações substanciais no perfil de sua produção, alterando a composição de suas exportações na direção dos tradables high tech.
} 


\section{DEFINIÇÕES E HIPÓTESES FUNDAMENTAIS DO MODELO: EXPLICANDO O EFEITO COMPOSIÇÃO}

Supõe-se que as exportações e importações sejam definidas de forma diferente do modelo de restrição externa, pois o mesmo considera a existência de apenas um bem. Tal definição não permite captar as mudanças nas elasticidades em decorrência do efeito composição, conforme exposto a seguir. No modelo seminal de Thirlwall, as exportações, importações e taxa de câmbio real são definidas, respectivamente, da seguinte forma:

$$
\begin{aligned}
& X=a E_{r}^{\eta} Z^{\varepsilon} \\
& M=b E_{r}^{-\psi} Y^{\pi} \\
& E_{r}=E P_{f} / P_{d}
\end{aligned}
$$

Em que $X$ representa as exportações, $M$ as importações, $E_{r}$ a taxa de câmbio real, $Z$ a renda mundial, $Y$ a renda doméstica, $a$ e $b$ são parâmetros constantes e, respectivamente, $\eta$ e $\psi$ representam as elasticidades preço das exportações e das importações, $\varepsilon$ e $\pi$ as elasticidades renda das exportações e das importações, sendo todos positivos. $E$ é a taxa de câmbio nominal, $P_{f}$ o preço externo e $P_{d}$ o preço doméstico. Colocando $X$ e $M$ em taxas de crescimento, tem-se que:

$$
x=\eta e_{r}+\varepsilon z
$$

$$
m=-\psi e_{r}+\pi y
$$

Considerando a taxa de crescimento da taxa de câmbio real $e_{r}$ igual a zero no longo prazo e $x=m$, chega-se à Lei de Thirlwall, $y=(\varepsilon / \pi) z$. Daí a conclusão de que, dada as elasticidades renda das exportações e das importações, a taxa de crescimento do produto doméstico se ajusta à taxa de crescimento da renda mundial ${ }^{6}$. A hipótese fundamental do modelo proposto é que essa relação $y / z$ se altera no longo prazo, pois as elasticidades mudam em função do efeito composição ocasionado pela mudança no nível da taxa de câmbio real. Os efeitos da taxa de câmbio real sobre a demanda agregada no curto prazo perduram no longo prazo a favor do desenvolvimento econômico quando seu nível é mantido num patamar estável e competitivo o tempo suficiente para endogeneizar nas elasticidades os efeitos benéficos do aumento das exportações, o que implica uma mudança na estrutura produtiva a favor dos tradables. A hipótese complementar do modelo tem inspira-

\footnotetext{
${ }^{6} \mathrm{O}$ argumento contrário apresentado por Krugman (1989), denominado regra de $45^{\circ}$, é que, no longo prazo, as elasticidades renda se ajustam a uma determinada relação entre a taxa de crescimento do produto doméstico e a taxa de crescimento do resto do mundo. O que se pretende aqui é produzir algo que represente um meio-termo entre esses dois argumentos.
} 
ção kaldoriana e considera que o aumento das exportações estimula a produção de tradables high tech, que é a principal responsável pela alavancagem do desenvolvimento econômico. Da mesma forma, considera-se que o aumento das exportações gera externalidades dinâmicas positivas em toda a economia, elevando a produtividade e competitividade dos produtos domésticos ${ }^{7}$.

O efeito composição refere-se à mudança das elasticidades provocada pela alteração na pauta de exportações e importações de um determinado país, no que diz respeito tanto à quantidade de bens que compõe a pauta quanto à participação relativa de cada um deles. Considere, por exemplo, a elasticidade renda das importações $(\pi)$, que é determinado da seguinte forma:

$$
\pi=\sum_{i=1}^{k} \theta_{i} \pi_{i}
$$

A pauta de importações de um país é composta por $k$ bens, cada um com uma elasticidade renda específica $\pi_{i}$, cuja contribuição na determinação de $\pi$ depende de sua participação em tal pauta $\theta_{i}$. Uma mudança no nível da taxa de câmbio real e sua estabilidade no longo prazo provocam uma alteração de $\pi$ por dois canais: a quantidade $k$ de bens que compõem a pauta de importações e o peso relativo de cada bem $\theta_{i}$. Por exemplo, a manutenção do nível da taxa de câmbio real depreciado e competitivo diminui a variedade de bens importados e concentra a pauta naqueles bens essenciais ao funcionamento da economia. Todavia, a elevação do nível de desenvolvimento implica a redução gradativa da necessidade de tais bens, pois passam a ser produzidos internamente para atender ao mercado doméstico e buscar sua inserção competitiva nos mercados externos. Assim, $\pi$ se altera no longo prazo. Decerto, a análise torna-se complexa a esse nível, tanto pela variedade de bens que compõem a pauta de importações quanto pelas diferentes reações de tais bens ao nível da taxa de câmbio real. Isso apontaria para um modelo multi-setorial. Dessa forma, algumas hipóteses simplificadoras serão introduzidas. Seguindo o modelo, as exportações e as importações serão divididas em duas categorias de bens conforme abaixo ${ }^{8}$ :

\footnotetext{
${ }^{7}$ Caso a produção de tradables low tech seja expandida, haverá prejuízo ao desenvolvimento econômico em função da apreciação cambial, que ocorrerá por dois motivos: aumento do influxo de divisas proveniente do aumento das exportações; aumento do preço dos bens non-tradables devido ao aumento da demanda interna. Isso inibe a produção do setor de tradables high tech e a geração de externalidades dinâmicas, pois capital e trabalho são deslocados para os setores de tradables low tech e non-tradables. Trata-se do que na literatura econômica denomina-se Dutch Disease. Para mais detalhes, ver Gala (2006, cap. 3).

${ }^{8}$ Diferentes categorias de tradables reagem de forma diferente à mudança no nível da taxa de câmbio real. Nesse caso, para simplificar, pode-se considerar que existem duas categorias: uma com maior conteúdo tecnológico (high tech) e outra com menor conteúdo tecnológico (low tech). Assim, considerando que o conhecimento tecnológico concentra-se nas exportações, a manutenção da taxa de câmbio real num nível depreciado e competitivo estimula o aumento das exportações, favorecendo a produção de tradables high tech, tendo em vista o aprendizado proveniente da competição em mercados externos dinâmicos e a atração de investimentos externos diretos que tal nível proporciona. Tendo em vista
} 


$$
X=X_{H T}+X_{L T}
$$

$$
M=M_{H T}+M_{L T}
$$

As exportações totais $X$ dividem-se em exportações de bens high tech $X_{H T} \mathrm{e}$ bens low tech $X_{L T}{ }^{9}$, assim como as importações. Em termos de taxa de crescimento, tem-se que:

$$
\begin{aligned}
& x=\phi x_{H T}+(1-\phi) x_{L T} \therefore 0<\phi<1 \\
& m=\theta m_{H T}+(1-\theta) m_{L T} \therefore 0<\theta<1
\end{aligned}
$$

Em que $\phi=X_{H T} / X$ e $\theta=M_{H T} / M$. As exportações e importações de bens high tech e low tech são definidas conforme abaixo:

$$
\begin{aligned}
& X_{H T}=a_{1} E_{r}^{\eta_{H T}} Z^{\varepsilon_{H T}} \\
& X_{L T}=a_{2} E_{r}^{\eta_{L T}} Z^{\varepsilon_{L T}} \\
& M_{H T}=b_{1} E_{r}^{-\psi_{H T}} Y^{\pi_{H T}} \\
& M_{L T}=b_{2} E_{r}^{-\psi_{L T}} Y^{\pi_{L T}} .
\end{aligned}
$$

Nas equações (11) a (14), cada categoria de bem possui elasticidades específicas, representadas por parâmetros positivos, e $a_{1}, a_{2}, b_{1} e b_{2}$ são as constantes das funções. Colocando em taxas de crescimento e substituindo em (9) e (10), chega-se a:

$$
\begin{aligned}
& x=\left[\phi \eta_{H T}+(1-\phi) \eta_{L T}\right] e_{r}+\left[\phi \varepsilon_{H T}+(1-\phi) \varepsilon_{L T}\right] z \\
& m=-\left[\theta \psi_{H T}+(1-\theta) \psi_{L T}\right] e_{r}+\left[\theta \pi_{H T}+(1-\theta) \pi_{L T}\right] y
\end{aligned}
$$

Imediatamente, observa-se o efeito composição, que se manifesta a partir da participação dos bens high tech na pauta de exportações e importações. Comparando (4) e (5) com (15) e (16), observa-se que as elasticidades são alteradas pelo efeito composição conforme abaixo:

tratar-se de uma economia pequena e semi-industrializada, os ganhos dessa política são substanciais. Para um argumento nesse sentido, ver Polterovich e Popov (2002).

${ }^{9}$ Em relação a essas duas categorias de bens, pode-se considerar que a primeira refere-se à produção de manufaturas de alto conteúdo tecnológico e bens de capital e a segunda à produção de commodities relacionada às riquezas naturais do país (petróleo, minério, bens agrícolas etc.). 


$$
\begin{aligned}
& \eta=\phi \eta_{H T}+(1-\phi) \eta_{L T} \\
& \varepsilon=\phi \varepsilon_{H T}+(1-\phi) \varepsilon_{L T} \\
& \psi=\theta \psi_{H T}+(1-\theta) \psi_{L T} \\
& \pi=\theta \pi_{H T}+(1-\theta) \pi_{L T}
\end{aligned}
$$

Será feita a suposição de que as elasticidades específicas $\left(\eta_{H T}, \eta_{L T}, \varepsilon_{H T}, \varepsilon_{L T}, \psi_{H T}\right.$, $\psi_{L T}, \pi_{H T}$ e $\left.\pi_{L T}\right)$ sejam dadas e que as elasticidades agregadas $(\eta, \varepsilon, \psi, \mathrm{e} \pi)$ preço e renda das exportações e importações sejam modificadas de acordo com a composição das pautas de exportações e importações, respectivamente, $\phi$ e $\theta$, cujas mudanças provêm do aumento das exportações high tech ${ }^{10}$.

Considerando que seja razoável supor que os bens high tech sejam mais inelástico-preço $\left(\eta_{H T}<\eta_{L T}\right.$ e $\left.\psi_{H T}<\psi_{L T}\right)$ e mais elástico-renda $\left(\varepsilon_{H T}>\varepsilon_{L T}\right.$ e $\left.\pi_{H T}>\pi_{L T}\right)$ do que os bens low tech, o comportamento das elasticidades pode ser estudado a partir de $\phi$ e $\theta$. Quanto maior $\phi$, mais elástico-renda (maior $\varepsilon$ ) e mais inelástico-preço (menor $\eta$ ) serão as exportações. Quanto menor $\theta$, mais inelástico-renda (menor $\pi$ ) e mais elástico-preço (maior $\psi$ ) serão as importações. Portanto, o aumento de $\phi$ e a redução de $\theta$ ao longo do tempo indicam uma melhora estrutural da relação de comércio de um país com o resto do mundo, aumentando a liquidez internacional sem a necessidade de aumentar as posições passivas com o exterior, pois se trata de um aumento estruturado nas exportações a partir de um nível de taxa de câmbio real depreciado e competitivo. Em outras palavras, o aumento da produção de tradables high tech e a geração de uma balança comercial favorável para esses bens ${ }^{11}$ representam a estratégia denominada acima de integração comercial ativa ou, nos termos de Williamsom (2003), a Development Strategy Approach da política cambial.

Outra hipótese fundamental do modelo refere-se à especificação funcional de

\footnotetext{
${ }^{10} \mathrm{O}$ argumento de que as externalidades existentes nas importações seriam as mais relevantes, o que justificaria uma política de apreciações cambiais, não encontrou campo fértil para comprovação empírica nos países da América Latina, onde se observou baixas taxas de crescimento e uma sequência de crises financeiras. Tais externalidades são limitadas, pois essa política é acompanhada de déficits nas transações correntes, aumento do débito externo, aumento do fluxo de capital especulativo e da vulnerabilidade externa. $\mathrm{O}$ argumento aqui é que as externalidades existentes nas exportações são mais relevantes, pois permitem, a partir de uma política de depreciação cambial, potencializar a capacidade de aprendizado inerente à competição em mercados externos dinâmicos, reforçado pelo aumento estruturado das reservas cambiais, redução da vulnerabilidade externa e aumento do fluxo de capital de longo prazo (países asiáticos).

${ }^{11} \mathrm{Em}$ termos dinâmicos, considere que $v=\phi / \theta$. A melhora estrutural na relação de comércio com o resto do mundo implica um crescimento dessa razão ao longo do tempo, ou seja, $\dot{v}=\left[\left(x_{H T}-x\right)-\left(m_{H T}-m\right)\right] v$. Para que essa diferencial seja positiva, a condição é que $x_{H T}-m_{H T}>x-m$, ou seja, considerando que o lado esquerdo dessa desigualdade seja positivo, o saldo comercial dos tradables high tech deverá crescer ao longo do tempo.
} 
$\phi$ e $\theta$ e à definição de seus argumentos. Por se tratar de razões que envolvem um componente fortemente tecnológico, é razoável supor que as mesmas possuem uma relação na forma de uma função logística com o nível da taxa de câmbio real, considerando que o aumento da razão $\phi / \theta$ represente melhorias no nível de desenvolvimento econômico. Isso pelo seguinte motivo. Inicialmente, um aumento no nível da taxa de câmbio real permitirá a introdução de inovações tecnológicas e sua difusão motivada pelas externalidades ligadas às exportações, o que acontece num ritmo lento, tendo em vista tratar-se de uma economia semi-industrializada e requerer mudanças substanciais no padrão de funcionamento da economia. Posteriormente, aumentos no nível da taxa de câmbio real possibilitarão iniciar um processo de difusão tecnológica, que ocorre num ritmo mais rápido, tendo em vista estarem assentadas as bases de um novo padrão tecnológico. Finalmente, níveis mais elevados da taxa de câmbio real passam a ter um menor efeito sobre o processo de difusão tecnológica. Assim, as razões $\phi$ e $\theta$ possuem as especificações abaixo:

$$
\begin{aligned}
& \phi=\frac{\phi_{\max }}{1+\phi_{1} e^{-\phi_{\min } E_{r}}} \\
& \theta=\frac{\theta_{\max }}{1+\theta_{1} e^{\theta_{\min } E_{r}}}
\end{aligned}
$$

De acordo com a equação (21), a participação dos tradables high tech na pauta de exportações possui uma relação não linear com o nível da taxa de câmbio real, variando entre um valor mínimo $\phi_{\min }$ e um valor máximo $\phi_{\max }$. Isso se deve ao fato de que os tradables high tech sempre terão uma participação mínima na pauta de exportações, mas nunca a mesma se concentrará integralmente nesses bens. A equação (22) mostra que ocorre o contrário com as importações. Os parâmetros $\phi_{1}$ e $\theta_{1}$ são positivos.

Implicitamente, considera-se que as mudanças nas pautas de exportações e importações ocasionadas pelas alterações no nível da taxa de câmbio real estão associadas a mudanças na estrutura produtiva doméstica a favor de produtos tecnologicamente mais sofisticados (tradables high tech) $)^{12}$, pois é assumido que existem externalidades positivas vinculadas ao aumento das exportações e à adoção de um nível de taxa de câmbio real subvalorizado e competitivo. Ou seja, o aumento

\footnotetext{
12 Para ser mais específico, o que está implícito é a ideia de que o produto doméstico é dividido em non-tradables, tradables high tech e tradables low tech, devendo-se isso à natureza da dinâmica das elasticidades, cuja mudança é incentivada pela demanda, mas passa necessariamente por uma mudança na estrutura produtiva doméstica. A interação com a demanda se dá pelas funções importações e exportações, porém com uma especificação diferente da usada por Thirlwall, visto que haveria dois tipos de bens tradables ao invés de um. Uma alternativa para o modelo seria quebrar o produto doméstico em absorção doméstica e saldo comercial, sendo que a dinâmica da restrição externa seria adequar o crescimento da absorção ao crescimento da produção. Todavia, nesse caso não seria possível verificar a natureza estrutural da restrição externa e levaria a um leque de política tal como proposto pelo enfoque monetário do balanço de pagamentos.
} 
da participação dos produtos high tech na pauta de exportações implica o aumento de sua produção, provocando impactos em outras variáveis relevantes da economia. Considera-se também implicitamente que a produção de produtos tecnologicamente mais sofisticados é responsável pelo aumento da taxa de crescimento do produto doméstico, já que possibilita o aumento da produtividade de todos os setores da economia, tal como suposto por Kaldor (1966 [1978], 1970 [1978]). Dessa forma, será trabalhado formalmente com a taxa de crescimento do produto doméstico agregado. Em resumo, um aumento e a manutenção da taxa de câmbio real num nível competitivo incentivarão um aumento nas exportações, que aumentará sua intensidade tecnológica pela mudança na estrutura produtiva doméstica devido à introdução de inovações tecnológicas e sua difusão na economia, aumentando a produtividade da economia e a taxa de crescimento do produto doméstico.

\section{UMA RECONSIDERAÇÃO SOBRE O PAPEL DA TAXA DE CÂMBIO REAL NO MODELO DE THIRLWALL}

O estudo econométrico feito por Gala (2006) aponta para o fato de que o nível da taxa de câmbio real é uma variável relevante para explicar as diferenças nas taxas de crescimento existentes entre os países. Além disso, os resultados comprovam a hipótese de que há uma correlação positiva entre desvalorizações da taxa de câmbio real e o crescimento do produto doméstico. As duas principais conclusões do trabalho são que: 1) por um lado, a política cambial não é neutra no longo prazo; 2) por outro, a política cambial é um forte fator que explica o sucesso dos países asiáticos em relação aos países da América Latina e da África em termos de desenvolvimento econômico.

O que se pretende aqui é incorporar tais resultados no modelo teórico de crescimento econômico com restrição externa e mostrar que, ao contrário do que é normalmente suposto, a taxa de câmbio real pode ser utilizada tanto para a melhoria da competitividade preço quanto na melhoria da competitividade não preço. Isso devido ao incentivo criado, via taxa de câmbio real, para aumentar as exportações, e às externalidades positivas provenientes desse aumento (inovações tecnológicas, aprendizado, acúmulo de reservas e atração de investimentos externos diretos). Tanto no modelo original quanto nas demais extensões, o papel da taxa de câmbio real foi considerado desprezível no longo prazo. Apesar de Barbosa-Filho (2001a e 2004) chamar a atenção para a importância da taxa de câmbio real, seu modelo enfatizou basicamente os aspectos de curto prazo da política macroeconômica. Todavia, a mesma pode ser utilizada para se obter resultados de longo prazo e o modelo de Thirlwall parece abrigar as possibilidades para especular sobre tais aspectos. Basta para isso especificar uma regra para as desvalorizações cambiais e introduzir o efeito composição na equação completa do modelo, o que implica tornar as elasticidades endógenas.

A primeira mudança em relação ao modelo de Thirlwall é a decomposição das exportações em tradables low tech e tradables high tech, uma vez que o aumento 
das exportações em função do câmbio subvalorizado irá gradativamente aumentar a intensidade tecnológica da pauta de exportações via externalidades provenientes do aprendizado inerente à competição em mercados externos dinâmicos. Num trabalho que visa argumentar a favor do acúmulo de reservas como instrumento para acelerar o crescimento econômico, tendo com base os países asiáticos, Polterovich e Popov (2002) ainda apontam as seguintes vantagens da adoção de um câmbio real subvalorizado: aumento do conhecimento acumulado e da produtividade, aumento do investimento doméstico, aumento do investimento externo direto em função da queda relativa do preço dos ativos reais domésticos na moeda local e do aumento da confiança dos investidores externos quanto à sustentabilidade do crescimento devido ao acúmulo de reservas cambiais. Na palavra dos autores, "por razões óbvias, países tecnologicamente atrasados têm muito mais ganhos a partir das externalidades das exportações e dos influxos de investimentos diretos externos do que os países avançados.” (Poltrovich e Popov, 2002, p. 163).

A segunda mudança em relação ao modelo de Thrilwall refere-se às elasticidades. Conforme visto na seção anterior, pode-se considerar que as elasticidades mudam à medida que a composição das pautas de exportação e importação se altera ao longo do tempo. Bairam (1997), num estudo econométrico, mostra que a elasticidade renda das exportações se altera em função de mudanças do produto per capita no longo prazo. Carvalho e Lima (2007) apresentam que a taxa de crescimento no Brasil no período 1930-2004 foi compatível com o equilíbrio no balanço de pagamentos, mas que a partir da década de 1990 houve uma quebra estrutural da elasticidade renda das importações em função da estratégia de desenvolvimento adotada. Tendo em vista que esse período foi marcado por apreciações cambiais, não há como desconsiderar que a taxa de câmbio real não tenha influenciado a quebra estrutural na elasticidade renda das importações mencionada acima. Será considerado aqui que as elasticidades renda das exportações e importações são funções lineares, respectivamente, das razões tradables high tech/ exportações totais e tradables high tech/importações totais. Rearranjando as equações (18) e (20), tem-se que:

$$
\begin{aligned}
& \varepsilon=\varepsilon_{L T}+\left(\varepsilon_{H T}-\varepsilon_{L T}\right) \phi \\
& \pi=\pi_{L T}+\left(\pi_{H T}-\pi_{L T}\right) \theta
\end{aligned}
$$

Conforme visto anteriormente, as elasticidades renda são positivas, sendo que $\varepsilon_{H T}>\varepsilon_{L T}$ e $\pi_{H T}>\pi_{L T}$. As equações acima mostram que quanto maior a intensidade tecnológica das exportações e das importações, maiores serão suas elasticidades renda. Tais hipóteses parecem bastante razoáveis. Por um lado, as baixas taxas de crescimento observadas no Brasil a partir da década de 1990 podem ser explicadas pela dita "perversidade" do equilíbrio externo em função do aumento da participação de bens com maior conteúdo tecnológico na pauta de importações e pelo aprofundamento da especialização brasileira em exportar commodities. Por outro lado, as elevadas taxas de crescimento observadas nos países asiáticos podem ter 
sido ocasionadas pelo aumento do conteúdo tecnológico das exportações e pela redução desse conteúdo das importações, tornando o equilíbrio externo mais "brando". Em outras palavras, no primeiro caso, houve um aperto da restrição externa (redução da razão entre as elasticidades renda das exportações e das importações), enquanto no segundo caso houve um afrouxo da restrição externa. Substituindo (21) em (23) e (22) em (24), chega-se à relação entre as elasticidades renda e o nível da taxa de câmbio real.

$$
\begin{aligned}
& \varepsilon=\varepsilon_{L T}+\frac{\left(\varepsilon_{H T}-\varepsilon_{L T}\right) \phi_{\max }}{1+\phi_{1} e^{-\phi_{\min } E_{r}}} \\
& \pi=\pi_{L T}+\frac{\left(\pi_{H T}-\pi_{L T}\right) \theta_{\max }}{1+\theta_{1} e^{\theta_{\min } E_{r}}}
\end{aligned}
$$

A equação (25) mostra que a elasticidade renda das exportações tende a aumentar (diminuir) mais rapidamente quando a taxa de câmbio real aumenta (diminui) para níveis intermediários e a aumentar (diminuir) mais vagarosamente para níveis extremos. A equação (26) mostra que a elasticidade renda das importações se movimenta de forma contrária. Decerto, as elasticidades renda não estão mudando constantemente, pois tal mudança decorre de um processo lento, o que requer certa estabilidade da taxa de câmbio real, cuja alteração seja alvo explícito de uma política econômica com foco no longo prazo. Nesse aspecto se insere um regime de metas de taxa de câmbio real com foco no desenvolvimento econômico.

Para que a política cambial produza efeitos estruturais na economia, deve-se estabelecer uma regra de ajustamento da taxa de câmbio real. A ideia é que, mesmo que a taxa de crescimento da taxa de câmbio real seja igual a zero no longo prazo, seu ajustamento para uma meta competitiva provoca efeitos além do ajuste da demanda agregada no curto prazo, pois tal ajuste e sua manutenção na meta competitiva altera as elasticidades renda (determinantes da restrição externa) num movimento favorável à relação de comércio do país em relação ao resto do mundo. Para simplificar, será estabelecida uma regra para as variações na taxa de câmbio real, definindo um nível desejado para a taxa de câmbio real, ou seja,

$$
e_{r}=x\left(E_{r}^{*}-E_{r}\right)
$$

Em $x>0, E_{r}^{*}$ representa a meta de taxa de câmbio real e $E_{r}$ a taxa de câmbio real compatível com o equilíbrio no balanço de pagamentos ${ }^{13}$. O parâmetro $\chi$ mede a velocidade de ajuste da taxa de câmbio real à meta estabelecida, sendo um parâmetro sob controle das autoridades monetárias. O estabelecimento de uma meta subvalorizada (sobrevalorizada) e competitiva (não competitiva) implicará

\footnotetext{
${ }^{13}$ A definição de taxa de câmbio real também é tema de ampla discussão. Sobre o assunto ver La Marca (2004). Aqui, de forma simplificada, está sendo suposto que existe um nível da taxa de câmbio real compatível com o equilíbrio no balanço de pagamentos, definido quando não há variações nas reservas cambiais. Implicitamente. É suposto também que esse nível é compatível com um nível estável dos preços domésticos.
} 
uma desvalorização (valorização) da taxa de câmbio real. A variação cessará tão logo a meta seja alcançada. Sem tecer mais detalhes, as equações (25), (26) e (27) permitem fazer uma releitura do modelo de Thirlwall sem fluxo de capitais, cuja equação completa é dada por:

$$
y=\frac{\varepsilon}{\pi} z+\frac{(\eta+\psi-1)}{\pi} e_{r}
$$

Thirlwall (1979) considera que $e_{r}=0$ no longo prazo, reduzindo (28) a $y / z=\varepsilon / \pi$, sendo que a taxa de crescimento do produto doméstico se ajusta à taxa de crescimento do resto do mundo, dada as elasticidades renda das exportações e importações. A evidência empírica encontrada em Gala (2006), Polterovich e Popov (2002) e, de certa forma, Carvalho e Lima (2007), dificilmente permite sustentar essa hipótese. Em primeiro lugar, desvalorizações na taxa de câmbio real geram um efeito expansionista de curto prazo via demanda agregada (aumento das exportações), o que é captado pelo segundo termo da equação (28), considerando que a condição Marshall-Lerner seja atendida. $\mathrm{O}$ argumento predominante é que tal efeito cessará tão logo se reverta em aumentos dos preços domésticos. Todavia, esse argumento desconsidera o fato de que a política macroeconômica pode assegurar as condições necessárias para que a taxa de câmbio real possa ser mantida num nível desvalorizado o tempo suficiente para gerar mudanças estruturais na economia em função das externalidades positivas existentes nas exportações. Em segundo lugar, as mudanças estruturais provenientes da manutenção da taxa de câmbio real num nível desvalorizado e competitivo dificilmente permitem sustentar a hipótese de que as elasticidades renda das exportações e importações permanecem constantes. Pelo contrário, o primeiro termo de (28) capta os efeitos de longo prazo de uma desvalorização da taxa de câmbio real sobre a relação entre a taxa de crescimento do produto doméstico e a taxa de crescimento do resto do mundo, uma vez que as elasticidades mudam em função de tal desvalorização.

Em resumo, a releitura do modelo de Thirlwall sem fluxo de capitais estabelece que, uma vez definida uma meta competitiva para o nível da taxa de câmbio real, $E_{r}^{*}$, haverá uma desvalorização do câmbio real até atingir o nível desejado pelas autoridades monetárias conforme a equação de ajuste (27). Isso fará com que haja uma mudança na composição da pauta de exportações e importações favoravelmente aos bens tecnologicamente mais sofisticados de acordo com (21) e (22), que por sua vez irá alterar as elasticidades conforme (23) e (24). Uma vez atingida a meta da taxa de câmbio real, sua taxa de crescimento volta a ser igual a zero e o segundo termo de (28) desaparece, o que requer que a política macroeconômica garanta a estabilidade da taxa de câmbio real ao nível competitivo. Todavia, mesmo que o efeito expansionista de curto prazo da demanda agregada cesse, o efeito de longo prazo da taxa de câmbio real sobre a taxa de crescimento do produto doméstico perdura por meio dos novos valores das elasticidades renda, $\varepsilon^{*}$ e $\pi^{*}$, compatíveis com o novo nível da taxa de câmbio real, $E_{r}^{*}$. Logo, o nível da taxa de câmbio real é um importante instrumento de política para o desenvolvimento eco- 
nômico ${ }^{14}$. Em comparação ao regime de metas de inflação, há uma inversão de causalidade no regime de metas de taxa de câmbio real: enquanto no primeiro, o produto doméstico, por meio das variáveis de controle das autoridades monetárias, se ajusta a taxa de inflação doméstica desejada, no segundo, a taxa de inflação doméstica se ajusta para alcançar e manter a taxa de câmbio real no nível desejado ${ }^{15}$. Isso requer uma melhor especificação de como a taxa de câmbio real pode atingir o nível desejado. Formalmente, isso pode ser verificado a partir da definição da taxa de crescimento da taxa de câmbio real.

$$
e_{r}=p_{f}+e-p_{d}
$$

Considerando que a inflação do resto do mundo é exógena, as desvalorizações da taxa de câmbio real dependem da taxa de câmbio nominal e da taxa de inflação. Substituindo (27) em (29), tem-se que:

$$
\chi\left(E_{r}^{*}-E_{r}\right)=p_{f}+e-p_{d}
$$

Uma vez estabelecida a meta de taxa de câmbio real, a taxa de câmbio nominal e a taxa de inflação irão se ajustar para alcançar o nível desejado $E_{r}^{*}$. Mais especificamente, conforme sugerido por Frenkel e Taylor (2006), a variável mais utilizada para influenciar a taxa de câmbio real é a taxa de câmbio nominal, cabendo às políticas monetária e fiscal controlar a taxa de inflação para permitir que o nível da taxa de câmbio real produza seus efeitos de longo prazo a favor do desenvolvimento econômico. Uma vez atingida a meta, formalmente, a estabilidade da taxa de câmbio real requer que:

$$
e=p_{d}-p_{f}
$$

A equação (31) mostra que, para assegurar os efeitos de longo prazo da taxa de câmbio real, a política macroeconômica deve garantir que a variação da taxa de câmbio nominal se ajuste ao diferencial de inflação doméstica e externa. Argumentando de outra forma, estabelecida uma meta de taxa de câmbio real e considerando a inflação do resto do mundo exógena, a política macroeconômica deve assegurar que $e$ e $p_{d}$ se ajustem para assegurar os efeitos sobre o produto doméstico da taxa de câmbio real subvalorizada e competitiva. Conforme sugere Frenkel e Taylor (2006), não se trata de uma tarefa trivial, tendo em vista os inúmeros fatores que afetam tais variáveis. Se $E_{r}$ é a taxa de câmbio real compatível com o equilíbrio no

\footnotetext{
${ }^{14} \mathrm{Em}$ termos metodológicos, pode-se dizer que há um processo de histerese na relação entre a taxa de crescimento do produto doméstico e a taxa de câmbio real. Isso porque, depois de cessado o processo de desvalorização da taxa de câmbio real, ou seja, ter atingido a meta estabelecida, o sistema mantém a "memória" do estímulo inicial com os novos valores das elasticidades compatíveis com a meta da taxa de câmbio real.

${ }^{15}$ Há outra contraposição entre esses regimes: no primeiro, o foco é de curto prazo e recessivo, enquanto, no segundo, o foco é de longo prazo e desenvolvimentista.
} 
balanço de pagamentos no qual não há mudanças nas reservas cambiais, pode-se supor que operações de compra e venda de moeda externa por parte das autoridades monetárias forcem movimentos na taxa de câmbio real conforme a direção da meta estabelecida.

Numa economia sem fluxo de capitais, a forma mais rudimentar de desvalorizar a taxa de câmbio é por meio de uma política deliberada de acúmulo de reservas cambiais. Conforme Polterovich e Popov (2002, p. 166), “[...] muitos países em desenvolvimento perseguem uma política consciente de desvalorização da taxa de câmbio como parte de sua estratégia orientada para o estímulo das exportações. Por meio da criação de pressões para tal desvalorização através do acúmulo de reservas cambiais, eles são capazes de limitar o consumo e as importações e estimular as exportações, investimento e crescimento econômico". Assim, é razoável supor que, considerando $R$ o nível de reservas compatível com o equilíbrio no balanço de pagamentos,

$$
E_{r}=E_{r}^{*}+\gamma\left(R-R^{*}\right)
$$

Em (32), $\gamma>0$ e é um parâmetro sob controle das autoridades monetárias; $R$ * representa o nível de reservas cambiais que irá, num primeiro momento, provocar uma variação na taxa de câmbio real na direção do nível desejado (meta) e, num segundo momento, garantir a manutenção da meta de taxa de câmbio real. Se $R=R^{*}, E_{r}=E_{r}^{*}$; se $R>R^{*}, E_{r}>E_{r}^{*}$ e as autoridades monetárias deverão vender moeda externa (reduzir reservas) para atingir a meta de taxa de câmbio real; se $R<R^{*}, E_{r}<E_{r}^{*}$ e as autoridades monetárias deverão comprar moeda externa (aumentar reservas) para atingir a meta de taxa de câmbio real. Portanto, a política de acúmulo de reservas e a prática deliberada de um nível subvalorizado da taxa de câmbio real referem-se a um desvio do nível de equilíbrio. Na terminologia de Polterovich e Popov (2002), refere-se a um regime desbalanceado. Há que mencionar ainda a assimetria que existe nas duas situações de desequilíbrio: enquanto a política de venda de reservas cambiais possui um limite, tendo em vista o estoque de moeda externa ser limitado e não ser o país doméstico seu emissor, a política de compra de reservas cambiais não possui tal limite, tendo em vista que a aquisição de moeda externa se dá com a moeda doméstica emitida pelo próprio país. Decerto, nesse último caso, as implicações são outras, mas, a princípio, não há limites para a aquisição de moeda externa.

De acordo com (32), quanto maior a meta de taxa de câmbio real, maior deverá ser o nível de reservas acumulado $R^{*}$ em relação ao nível de equilíbrio $R$. Observe que não se trata de um acúmulo passivo de reservas cambiais para evitar valorizações excessivas da taxa de câmbio real, tal como normalmente ocorre em países que sofrem de Dutch disease, ou quando ocorre um grande influxo de capitais, não sendo esse o caso considerado aqui. Pelo contrário, na visão de Polterovich e Popov (2002), as reservas passam a ser um instrumento de política para alavancar o desenvolvimento econômico.

Nessa versão adaptada da ideia dos autores, a variação das reservas atende a 
uma meta de taxa de câmbio real. Sem maiores detalhes, percebe-se facilmente que tal política requer uma política fiscal e monetária adequada para controlar os preços domésticos em decorrência do aumento da oferta monetária ${ }^{16}$. Ou seja, um aumento das reservas cambiais irá provocar uma expansão monetária e uma pressão para reduzir a taxa de juros, gerando uma expansão da demanda agregada via aumento do consumo e do investimento doméstico ${ }^{17}$. A pressão dessa expansão sobre os preços domésticos, o que causaria uma queda da meta de taxa de câmbio real estabelecida, pode ser contida por uma política de superávit primário e/ou aumento da dívida pública interna para enxugar a liquidez da economia. Deve-se considerar também que o aumento da capacidade produtiva, decorrente do aumento do investimento doméstico e do investimento direto externo ${ }^{18}$, pode contrabalancear, ou até mesmo eliminar, a pressão sobre os preços domésticos.

Uma questão que merece uma análise teórica um pouco mais detalhada refere-se aos impactos do aumento da taxa de crescimento do produto doméstico. $\mathrm{Ou}$ seja, se a adoção de um câmbio subvalorizado e competitivo produz um efeito tão positivo na economia, por que não se adota o mais alto nível de taxa de câmbio real possível para alcançar elevadas taxas de crescimento do produto doméstico? Decerto, devem existir mecanismos na economia que impeçam que isso ocorra, ou seja, o próprio aumento da taxa de crescimento do produto doméstico decorrente da política acima deve causar impactos que, em algum momento, irão "frear" o processo, impedindo que um determinado país conviva por um longo período com taxas elevadas de crescimento. Esse momento pode estar antes ou depois de se alcançar os efeitos positivos plenos de um nível de câmbio subvalorizado e competitivo: a Argentina recente é um exemplo do primeiro caso e o Japão dos anos 80 é um exemplo do segundo caso. Enquanto no primeiro a inflação interrompeu a mudança estrutural da economia decorrente de um câmbio real subvalorizado, no segundo a valorização do câmbio real ocorreu depois que se completou o processo de catching-up permitido pela adoção do câmbio real subvalorizado.

\section{O REGIME DE METAS DE TAXA DE CÂMBIO REAL NO MODELO DE THIRLWALL E OS EFEITOS KALDOR-VERDOORN E HARROD-BALASSA-SAMUELSON}

\footnotetext{
${ }^{16}$ De forma simplificada, $\Delta R=\Delta M+\Delta R P+\Delta D P I$, em que $M$ é a oferta monetária, $R P$ o resultado primário do governo e $D P I$ a dívida pública interna.

${ }^{17}$ Decerto, deverá existir um nível da taxa de juros compatível com a taxa de inflação que permita sustentar a meta de taxa de câmbio real ao longo do tempo.

${ }^{18} \mathrm{O}$ aumento do investimento direto externo certamente depende de outros fatores, tais como a comparação entre as rentabilidades dos ativos reais e financeiros. Mas o aumento das reservas cambiais e a queda dos ativos reais domésticos em moeda externa funcionam com fortes atrativos para tais investimentos. O exemplo típico desse fato é a China, que passa de um volume de investimentos diretos externos na ordem de US\$ 3 bi no início da década de 1990 para US\$ 50 bi em 2003.
} 
Os países em desenvolvimento que adotaram a estratégia de integração comercial ativa por meio de um câmbio real subvalorizado e competitivo experimentaram um aumento de produtividade e competitividade, consubstanciado na mudança da pauta de exportações a favor de bens tecnologicamente mais sofisticados. Nesse aspecto, há algumas lacunas no modelo de Thirlwall (1979). Em primeiro lugar, não foi considerado que a taxa de câmbio real pode ser um importante instrumento para melhoria da competitividade não preço. Em segundo lugar, também não foram levado em consideração os efeitos sobre a produtividade doméstica de uma melhora na taxa de crescimento do produto doméstico. Finalmente, não há nada que cubra a relação entre produtividade e taxa de câmbio real. A inter-relação entre os assuntos mencionados acima ao menos incita a algumas especulações teóricas a partir de modelos complementares.

$\mathrm{Na}$ releitura proposta acima, a melhoria da restrição externa (endogeneidade das elasticidades) sintetiza a forma como a taxa de câmbio real pode atuar a favor do desenvolvimento econômico. Decerto, tal melhora tem um impacto sobre a produtividade doméstica, que pode ser representado formalmente pelo efeito Kaldor-Verdoorn proveniente do modelo export led de Kaldor (1970 [1978]), conforme abaixo:

$$
r_{d}=r_{a}+\lambda y
$$

Em (33), $r_{d}$ representa a taxa de crescimento da produtividade do trabalho doméstica; $r_{a}$ concentra a influência de outras variáveis sobre o crescimento da produtividade (educação, infraestrutura e ambiente institucional); $\lambda$ representa $o$ coeficiente de Verdoorn, que varia no intervalo entre 0 e 1 . O uso de um câmbio real subvalorizado e competitivo permitirá a um país em desenvolvimento ter taxas de crescimento do produto doméstico mais elevadas. Assim, diferentemente da formalização de Thirlwall e Dixon (1975) do modelo de Kaldor, $y$ contém explicitamente o papel da taxa de câmbio real sobre a competitividade não preço, uma vez que leva em consideração a melhoria tecnológica proveniente das externalidades ligadas às exportações e ao câmbio subvalorizado, captado pela mudança nas elasticidades renda. Quanto maior $y$, maior será a taxa de crescimento da produtividade doméstica $r_{d}$, em função dos retornos crescentes e dos ganhos tecnológicos.

Dificilmente ocorrerá uma alteração na taxa de crescimento da produtividade doméstica sem que afete a taxa de câmbio real, tendo em vista seu impacto direto sobre os preços domésticos via salários monetários. Kaldor (1970 [1978]) não chega a abordar esse assunto no seu modelo de crescimento liderado pelas exportações. A hipótese mais conhecida sobre a relação entre taxa de câmbio real e produtividade do trabalho advém dos trabalhos de Harrod (1933), Balassa (1964) e Samuelson (1964), que ficou disseminada na literatura como efeito Harrod-Balassa-Samuelson. Trata-se de uma tentativa de demonstrar que a hipótese amplamente utilizada nos modelos neoclássicos da paridade do poder de compra (PPC) é parcialmente válida em função da existência dos bens non-tradables, o que explicaria o fato do preço nos países ricos ser superior aos preços nos países po- 
bres. Ou seja, as divergências dos preços seriam explicadas pelo diferencial de produtividade.

A ideia é que, no mercado internacional, a produtividade tende a divergir (mais alta nos países ricos e mais baixa nos países pobres) e os preços a convergir no setor de tradables, enquanto a produtividade tende a convergir e os preços a divergir (preços mais altos nos países ricos e preços mais baixos nos países pobres) no setor de non-tradables. A elevada produtividade dos países ricos no setor de tradables gera um aumento dos salários em todos os setores da economia, sendo que para o setor de non-tradables a única forma de absorver esse aumento ocorre por meio da elevação dos preços. O resultado é um índice de preço doméstico mais elevado nos países ricos. Já nos países pobres, a baixa produtividade do setor de tradables associa-se a baixos salários, não gerando pressão para aumento de preços dos non-tradables. O resultado é um índice de preço doméstico mais baixo nos países pobres. Como a taxa de câmbio real é fortemente dependente dos preços relativos, a conclusão é que um aumento (redução) na produtividade gera apreciações (depreciações) no câmbio real ${ }^{19,20}$.

Para simplificar a representação formal dessa ideia, pode-se considerar que o nível da taxa de câmbio real depende do diferencial de produtividade externa e doméstica (produtividade relativa) ${ }^{21}$. Sendo assim,

$$
E_{r}=E_{r^{0}}\left(\frac{R_{f}}{R_{d}}\right)^{E_{r 1}}
$$

Em (34), $E_{r 0}$ representa o nível autônomo da taxa de câmbio real, $R_{f}$ o nível da produtividade externa, $R_{d}$ o nível da produtividade doméstica. $E_{r 1}$ é um parâmetro positivo. Aplicando logaritmo e fazendo o diferencial total, chega-se a:

\footnotetext{
${ }^{19}$ O exemplo amplamente citado é o caso do Japão nos anos 1980 e 1990, em que o forte crescimento da produtividade do trabalho no setor de tradables gerou um extenso ciclo de apreciação da taxa de câmbio real, acompanhada, posteriormente, de perda de competitividade no mercado internacional.

${ }^{20} \mathrm{Na}$ verdade, a hipótese de que não há ganhos de produtividade no setor de non-tradables parece ser muito forte. Recentemente, o aumento da produtividade no setor de serviços, por exemplo, advindo das novas tecnologias da informação e comunicação, é bastante significativo. Nesse sentido, seria mais coerente pensar num crescimento balanceado da produtividade que beneficiasse tanto o setor de tradables quanto o setor de non-tradables. O que se verifica nessa situação é que o aumento da produtividade da economia como um todo levaria a uma queda no índice de preço doméstico. Logo, a conclusão é que um aumento (redução) na produtividade gera depreciações (apreciações) no câmbio real. Para estudo empírico do efeito Harrod-Balassa-Samuelson, ver, por exemplo, Zini Jr. e Cati (1993) e Vasconcelos (2004). Para um survey realizado recentemente, ver Tica e Druzic (2006). A maioria dos casos corrobora o efeito Harrod-Balassa-Samuelson, apesar de haver algumas evidências em contrário.
}

${ }^{21}$ A representação formal normalmente utilizada refere-se ao diferencial de produtividade relativa entre tradables e non-tradables, ou seja $E_{r}=E_{r^{\circ}}\left(\frac{R_{f r} / R_{A N T}}{R_{d T} / R_{d N T}}\right)^{E_{n}}$. Quanto maior a produtividade doméstica dos tradables em relação aos non-tradables comparativamente à economia externa, menor o nível da taxa de câmbio real. 


$$
e_{r}=e_{r^{0}}+E_{r 1}\left(r_{f}-r_{d}\right)
$$

A equação (35) mostra que, dada a taxa de crescimento da produtividade externa, a taxa de câmbio real se valoriza à medida que a taxa de crescimento da produtividade doméstica aumenta. Combinando as equações (33) e (35), tem-se que:

$$
e_{r}=e_{r^{0}}+E_{r 1}\left(r_{f}-r_{a}-\lambda y\right)
$$

O que se verifica com a equação (36) é que, se os efeitos Kaldor-Verdoorn e Harrod-Balassa-Samuelson coexistem, aumentos na taxa de crescimento do produto doméstico serão revertidos em valorizações na taxa de câmbio real. Isso modificaria os resultados teóricos apresentados na seção anterior. Países em desenvolvimento que adotem uma meta de taxa de câmbio real que leve a um grau de desenvolvimento muito elevado passam a conviver com uma pressão para a valorização da taxa de câmbio real. Trata-se, portanto, de um mecanismo que surge de seus efeitos positivos sobre a economia e que irá "frear" o ritmo de desenvolvimento econômico, a menos que as autoridades monetárias mantenham o nível da taxa de câmbio real administrativamente subvalorizado e competitivo por meio do acúmulo de reservas. Ou seja, apesar de parecer contraintuitivo, a pressão para a valorização da taxa de câmbio real surge dos efeitos positivos da adoção de um nível de taxa de câmbio subvalorizado e competitivo. Nesse caso, a regra de ajustamento representada pela equação (27) e a política de acúmulo de reservas teriam uma finalidade distinta. Conforme Polterovich e Popov (2002, p. 170), "Se o efeito [Harrod-Balassa-Samuelson] existe, o acúmulo de reservas cambiais, outras coisas permanecendo constantes, provocaria apenas pequenos aumentos na taxa de câmbio real, visto que a política das autoridades monetárias seria mais para prevenir apreciações cambiais". A equação (32) mostra que, para manter a meta de taxa de câmbio real, o nível desejado de reservas deve aumentar.

De certa forma, isso retrata a estratégia dos países asiáticos: i) inicialmente, praticaram uma política que elevou a taxa de câmbio real para um nível subvalorizado e competitivo; ii) posteriormente, adotaram uma política para manter a taxa de câmbio real nesse nível, promovendo as mudanças estruturais inerentes à estratégia de integração comercial ativa; iii) recentemente, tem sido comum adotarem uma política de acúmulo de reservas para evitar que a taxa de câmbio real saia de seu nível competitivo em função das pressões de valorização decorrentes do elevado grau de desenvolvimento atingido. Ou seja, a política de acúmulo de reservas começa operando no sentindo de desvalorizar a taxa de câmbio real para um nível competitivo e posteriormente, num estágio avançado, tal política atua no sentido de evitar valorizações na taxa de câmbio real a partir daquele nível. De uma ponta à outra, ocorre o processo de desenvolvimento econômico liderado pelas exportações ${ }^{22}$.

\footnotetext{
${ }^{22}$ Para uma análise empírica da relação desenvolvimento e política cambial na China, ver Vieira (2006).
} 
Verifica-se que, ao complementar a releitura do modelo de Thirlwall feita na seção anterior com os efeitos Kaldor-Verdoorn e Harrod-Balassa-Samuelson, metas elevadas de taxas de crescimento irão provocar pressões para valorizações cambiais a partir de um nível subvalorizado e competitivo da taxa de câmbio real. Novamente, o instrumento mais indicado para evitar que haja tais valorizações e se reverta o processo de crescimento econômico passa pela política de acúmulo de reservas. Logo, essa política possui dois momentos: inicialmente, a compra de moeda externa provoca uma desvalorização cambial para um nível competitivo estabelecido pelas autoridades monetárias; posteriormente, devido ao aumento das exportações e das elevadas taxas de crescimento, a compra de moeda externa passa a evitar um processo de valorização cambial a partir de um nível subvalorizado. A manutenção do câmbio real subvalorizado e competitivo requer um volume crescente de reservas cambiais. Esse aumento implica expansão da oferta monetária. Nesse caso, tal fato pode constituir-se num segundo mecanismo para "frear" os efeitos de um câmbio real subvalorizado e competitivo sobre a taxa de crescimento do produto doméstico.

\section{NOTAS FINAIS SOBRE O PAPEL DA TAXA DE CÂMBIO REAL NOS MODELOS DE RESTRIÇÃO EXTERNA}

Neste artigo, buscou-se realizar uma breve tentativa de dar uma nova interpretação teórica quanto ao papel da taxa de câmbio real nos modelos de crescimento econômico com restrição externa. Conforme visto, o principal esforço incidiu sobre a incorporação de diversas argumentações teóricas no modelo seminal de Thirlwall (1979), tendo como motivação inicial a argumentação da macroeconomia do desenvolvimento segundo a qual a taxa de câmbio real não é neutra no longo prazo. Conforme argumentado por Frenkel e Taylor (2006) e Barbosa-Filho (2006), mesmo que a taxa de crescimento da taxa de câmbio real seja considerada igual a zero no longo prazo, o que constitui um fato estilizado, o seu nível é um instrumento estratégico para o desenvolvimento econômico, permitindo que os preços relativos exerçam seu papel estrutural sobre a economia. As principais conclusões são as seguintes.

A adoção de um regime de meta de taxa de câmbio real difere de um regime de metas de inflação, uma vez que, enquanto o primeiro tem um viés de alto crescimento, o segundo tem um viés de baixo crescimento. A hipótese de que o nível da taxa de câmbio real altera, via efeito composição, as elasticidades representa um possível avanço nos modelos de crescimento com restrição externa. Decerto, os desafios metodológicos e formais são amplos ainda, mas foi possível representar formalmente uma ideia que pode alterar os principais resultados teóricos dessa família de modelos. Partindo de uma posição de equilíbrio, uma política deliberada de acúmulo de reservas leva a desvalorizações na taxa de câmbio real até o nível desejado, perfazendo um efeito de curto prazo e um efeito de longo prazo.

Em países que possuem alta instabilidade da taxa de câmbio real, devido pro- 
vavelmente aos processos inflacionários agudos associados à volatilidade da taxa de câmbio nominal, há uma distorção quanto à natureza da restrição externa. Os saldos comerciais positivos alcançados devido a uma desvalorização repentina da taxa de câmbio nominal, fruto de algum choque externo, pode levar à visão errônea de que a restrição externa tenha sido eliminada, ao passo que tal restrição não se refere a posições de curto prazo na balança comercial. O afrouxamento da restrição externa, quando essa é a restrição relevante ao crescimento econômico, com posições deficitárias na balança comercial e dependência dos fluxos internacionais de capital, apenas ocorre quando é eliminada a rigidez estrutural deficitária na balança comercial. Nesse sentido, a proposta foi fazer um exercício teórico formal para apontar um possível caminho para a alteração estrutural da relação de comércio de um país com o resto do mundo.

A introdução da ideia defendida pela macroeconomia do desenvolvimento a respeito do papel da taxa de câmbio real permitiu, por um lado, fazer uma análise em termos de política macroeconômica em modelos de restrição externa, o que não é possível, a princípio, caso se adote a hipótese de que a taxa de crescimento da taxa de câmbio real seja igual a zero, perfazendo o fato estilizado indicado por Thirlwall; por outro lado, permitiu avançar na extensão do modelo de Thirlwall elaborada por Barbosa-Filho (2001a) ao apontar o papel da taxa de câmbio real não apenas para o ajuste de curto prazo, mas também para as mudanças estruturais de longo prazo advindas do manejo da política macroeconômica em prol de uma política de desenvolvimento e não de uma política de estabilização, com baixas taxas de crescimento.

Uma questão relevante é que, se a adoção de uma taxa de câmbio real num nível subvalorizado e competitivo gera melhorias em termos de taxa de crescimento do produto doméstico, poderia pensar em adotar o maior nível possível para se obter taxas elevadas de crescimento numa escalada ilimitada. Todavia, conforme se argumentou, há limites pelo lado real e monetário da economia. Se os efeitos Kaldor-Verdoorn e Harrod-Balassa-Samuelson coexistem, o aumento da produtividade doméstica começa a contrapor os efeitos positivos de um câmbio subvalorizado, devendo intensificar a política de acúmulo de reservas cambiais. A necessidade crescente de acumular reservas provoca uma elevação da dívida pública interna e do superávit primário do governo, a depender da relação entre a taxa de juros real doméstica e a taxa de crescimento do produto doméstico, contribuindo para "frear" os efeitos benéficos da política cambial.

\section{REFERÊNCIAS BIBLIOGRÁFICAS}

BALASSA, B. (1964) “The purchasing power parity doctrine: a reappraisal”. Journal of Political Economy, 72(6): 584-596.

BALASSA, B. (1993) Policies choices for the 1990s. London: Macmillan.

BAIRAM, E. (1997) "Levels of economic development and appropriate specification of the Harrod foreign-trade multiplier”, Journal of Post Keynesian Economics, 19(3): 337-344. 
BARBOSA-FILHO, N. H. (2001a) "The balance-of-payments constraint: from balanced trade to sustainable debt”, Banca Nazionale del Lavoro Quarterly Review, 54(219): 381-400.

BARBOSA-FILHO, N. H. (2001b) “International liquidity and growth in Brazil”, New York, CEPA: Working Paper 2001.4.

BARBOSA-FILHO, N. H. (2004) "Growth, exchange rate and trade in Brazil: a structuralist post-Keynesian approach", Nova Economia, 14(2): 59-86.

BARBOSA-FILHO, N. H. (2006) "Exchange rates, growth and inflation". In Conference on Development and Change, Campos do Jordão. Disponível em http://www.policyinnovations.org/ideas/ policy_library/data/01383.

BRESSER-PEREIRA, L. C. \& NAKANO, Y. (2003) “Crescimento com poupança externa?”, Revista de Economia Política, 22(2): 3-27.

BRESSER-PEREIRA, L. C. \& VARELA, C. (2004) "The second Washington Consensus and Latin American's quase-stagnation”, Journal of Post Keynesian Economics, 27(2): 231-250.

BRESSER-PEREIRA, L. C. (2011) "Structuralist macroeconomics and new developmentalist", São Paulo, FGV: Texto para Discussão $\mathrm{N}^{\circ} 298$.

CARVALHO, V. R. \& LIMA, G. T. (2007) “A restrição externa e a perda de dinamismo da economia brasileira: investigando relações entre estrutura produtiva e crescimento econômico”. In XXXV Encontro Nacional de Economia da ANPEC, Recife. Disponível em http://www.anpec.org.br/ encontro2007/artigos/A07A013.pdf.

DOOLEY, M.; FOLKERTS-LANDAU, D. \& GARBER, P. (2003) "As essay on the revived Bretton Woods System”, Cambridge, Mass.: NBER Working Paper No 9971.

FRENKEL, R. (2004) "Real exchange rate and employment in Argentina, Brazil, Chile and Mexico". In XIX G24 Technical Group Meeting, Washington. Disponível em http://policydialogue.org/files/ events/Frenkel_Exchange_Rate_Employment.pdf.

FRENKEL, R. \& TAYLOR, L. (2006) "Real exchange rate, monetary policy and employment: economic development in garden of forking paths". In Conference Alternatives to Inflation Targeting Monetary Policy for Stable and Egalitarian Growth in Developing Countries, Buenos Aires. Disponível em http://www.policyinnovations.org/ideas/policy_library/data/01287.

GALA, P. (2006) “Política cambial e macroeconomia do desenvolvimento". Tese de Doutorado, São Paulo: FGV-SP. Disponível em http://www.eumed.net/tesis/2007/psosg/.

HARROD, R. (1933) Internacional Economics. London: CUP.

KALDOR, N. (1966 [1978]) “Causes of the slow rate of economic growth in the United Kingdom”. In KALDOR, N., Further essays on economic theory. New York: Holmes \& Meier, 1978: 100-138. . (1970 [1978]) “The case for regional policies". In KALDOR, N., Futher essays on economic theory. New York: Holmes \& Meier, 1978: 139-154.

KRUGMAN, P. (1989) "Differences in income elasticities and trends in real exchange rates", European Economic Review, 33(5): 1031-1046.

LA MARCA, M. (2004) "Real exchange rate, competitiveness and policy implications: a formal analysis of macroeconomics macro models", New York, CEPA: Working Paper 2004.2.

McCOMBIE, M. (1998) "Harrod, economic growth and international trade". In RAMPA, G. et al. (eds.), Economic dynamics, trade and growth: essays on Harrodian themes. London: The MacMillan Press, p. 212-244.

POPOV, V. \& POLTEROVICH, V. (2002) “Accumulation of foreign exchange reserves and long term growth". Moscow: New Economic School. (Unpublished paper).

RODRIK, D. (1986) "Disequilibrium exchange rates as industrialization policy", Journal of Development Economic, 23(1): 89-106.

SAMUELSON, P. (1964) “Theoretical notes on trade problems”, Review of Economics and Statistics, 46(2): $145-154$.

THIRLWALL, A. P. (1979) "The balance of payments constraint as an explanation of international growth rates differences", Banca Nazionale del Lavoro Quarterly Review, 32(128): 45-53.

THIRLWALL, A. P. \& DIXON, R. (1975) "A model of regional growth-rate difference on Kaldorian lines”, Oxford Economic Papers, 27(2): 201-214. 
TICA, J. \& DRUZIC, I. (2006) “The Harrod-Balassa-Samuelson effect: a survey of empirical evidence”, Zagreb: Working Paper Series $\mathrm{N}^{\circ}$ 06-07.

VASCONCELOS, C. R. F. (2004) "O efeito Balassa-Samuelson e a paridade do poder de compra na economia brasileira", Revista de Análise Econômica, 22(41): 101-116.

VIEIRA, F. V. (2006) “China: crescimento econômico de longo prazo”, Revista de Economia Política, 26(3): 401-424.

ZINI Jr., A. \& CATI, R. (1993) "Cointegração e taxa de câmbio: testes sobre a PPP e os termos de troca no Brasil de 1855 a 1990", Pesquisa e Planejamento Econômico, 23(2): 349-374.

WILLIAMSON, J. (2003) "Exchange rate policy and development". In Initiative for Policy Dialogue Task Force on Macroeconomics, New York.

. (2005) Curbing the boom-bust cycle: stabilizing capital flows to emerging markets., Washington: Institute for International Economics.

WOO, W. T. (2004) "Some fundamental inadequacies of the Washington Consensus: misunderstanding the poor by the brightest". In Conference on Stability, Growth and Search for a new development agenda: reconsidering the Washington Consensus, Santiago. 